\title{
Explorations in Ethnobiology: The Legacy of Amadeo Rea
}

\author{
Marsha Quinlan and Dana Lepofsky, eds. 2013. Society of Ethnobiology, Denton, TX. Pp. 310, color illustrations, \\ maps, tables. $\$ 56.95$ (paperback). ISBN 978-0988733008.
}

Reviewed by Raymond Pierotti

Reviewer address: Ecology and Evolutionary Biology, University of Kansas, Lawrence, KS 66045-2106. pierotti@ku.edu

Received: August 11, 2014

Volume: 5:126-128

Published: November 13, 2014

\section{(C) 2014 Society of Ethnobiology}

Explorations in Ethnobiology: The Legacy of Amadeo Rea (EiE) begins with a short article by Rea setting the tone by pointing out how Western attempts at economic development often destroy both local diversity and long-term management schemes developed by Indigenous peoples, a theme repeated in several chapters. Another key theme is evident in Rea's statement: “...we westerners are saturated from birth to death with the values of consumerism and progress through advanced technology, so much so that it is almost impossible for us to conceive of anyone thinking differently" (p., 6), which reinforces the point that Western approaches should not be automatically privileged over those of peoples who have lived in their places, interacting with their fellow species for centuries, if not millennia.

Similar themes are established in chapter 3, Ten Principles of Ethnobiology, in which Lepofsky interviews Rea. Rea says, for example, "Many cultures specify appropriate ways of interacting with their biological worlds that are, in turn embedded in more general rules about the right way to live. Understanding the complexity of peoples' relationships with their biological worlds, and how these relationships are expressed within specific cultures, are fundamental goals of ethnobiological research" (p. 41).

These principles deal with the interdisciplinary, cross-cultural, mutually respectful nature of top flight ethnobiological research. The relationships that Indigenous peoples have with their landscapes and of careful listening are discussed along with the necessity of keeping in mind potential applied aspects of such research. For example, scholars can find themselves testifying before courts or legislatures as experts on the cultures of people of which they are still outsiders. If this is done effectively, they can give back to the community that is important to their personal and professional growth.

Johnson and Kingsley provide an overview of Rea's career. A couple of important points about Rea are that he began his professional career as a Franciscan Friar and proved to be a highly effective biology teacher at a reservation high school. This experience led Rea into the study of ornithology within a nonWestern cultural context, which launched his scholarly career and helped establish the discipline of ethnobiology.

My early memories of Rea come from our time as budding ornithologists in the 1970s, where Amadeo presented his innovative idea that comparative behavior could be used to establish taxonomic relationships, providing evidence that vultures and storks were closely related. This concept may have come from his work with Indigenous peoples, who classify storks as a form of vulture.

Several chapters deal with Rea's legacy as an ornithologist, including chapter 9 by Kay Fowler about the ethnoornithology of one band of Northern Paiute, chapter 10 by Jan Timbrook and John Johnson concerning the avian knowledge of the Chumash, and chapter 12 by Carothers, House, and Johnson on endangered species and habitat destruction. Other chapters deal with Rea's influence on ethnobotany in the Southwestern US and Northern Mexico. Chapter 5 by Hodgson discusses the preColumbian introduction of domestic agave. In chapter 6 Brown et al. discuss paleobiolinguistics and domesticated squash.

Only one chapter deals specifically with archaeology: Charmion McCusick's chapter 11 on the ecological conclusions that can be drawn based upon evidence from ruins in the Upland Salado between the 
Salt and Gila Rivers near Globe, Arizona. This paper feels somewhat disconnected from the other papers, which seem to be divided between ethnographic studies and philosophical or theoretical arguments.

One area for which Rea, Nabhan, Hunn, Anderson, Fowler, and many scholars in this volume should be congratulated is in their ready acceptance of statements by Indigenous peoples as solid forms of evidence, which can contribute to scientific understanding. Too often statements, or accounts, by Indigenous people are relegated to what Anderson describes as "hot cognition," which is set in opposition to the "cool cognition" of the scientific method. A somewhat benign form of this attitude is the description of Indigenous people as being "mystical," hence not in touch with reality. Another, more noxious form, is description of Indigenous accounts of experienced relationships between different species, including humans, as "fairy tales" or "myths."

Archaeological findings and ethnographic accounts seem to function best when they compliment one another. The advantages of archaeological data are revealed in chapter 10 by Timbrook and Johnson in their evaluation of Harrington's ethnological data on the Chumash people of the south central California coast. Accounts recorded by Harrington, which rely primarily on the memories of a few elders, seem to omit some crucial groups, e.g., alcids (murres and auklets), from the account of important avian food sources, whereas the archaeological data included in this paper reveal the importance of this group, at least to island Chumash populations.

There are a series of insightful essays on more general topics by Gene Anderson (chapter 4), Gary Nabhan (chapter 7), Gene Hunn (chapter 8), and an elegant closing (chapter 13) by Nancy Turner and several First Nations collaborators.

One theme emerging from several essays is how important indigenous people are to local ecology and how they have profound observational knowledge of the organisms that share the places where they coexist. This theme is well presented in Anderson's What Shapes Cognition? Traditional Sciences and Modern International Science. Anderson argues cogently that different perceptions that emerge from specific cultural traditions represent different but equivalent ways of seeing and comprehending interactions between species and other natural phenomena because knowledge, including Western scientific knowledge, is socially constructed. The manner in which Anderson develops this argument involves an examination of aspects of knowledge that seem either "natural" or "supernatural" and that Western science tries to limit itself to the former, which restricts its usefulness in some ways because it cannot address issues that are not easily quantifiable; e.g., are nonhumans capable of emotional responses or do they have cultural traditions.

Hunn's essay, "Dog" as a Life Form, addresses important issues concerning systematics. Few biological ethnobiologists address theoretical issues, such as the correct approach to phylogenetic analysis. Hunn points out that most humans elevate the concept of 'Dog' to a status that might be more properly associated with a taxonomic genus or family, because the way in which we parse the diversity within this "life-form." Folk taxonomy runs counter to contemporary DNAbased canid phylogeny, in which 'Dog' has become a sort of orphaned but aggregate grouping with no proper scientific name, considered to be a domestic form of wolf, the wild ancestor of all "dogs." Confusion generated by DNA-based interpretations has caused numerous local governments to pass unenforceable, problematic laws, because of difficulties in in dealing with 'dogs' who are close to their wolf ancestors, as opposed to most 'recognized breeds' which are clearly domestic animals. Other articles in $E i E$ address systematic issues, such as Hodgson's excellent discussion of how the presence of "domesticated forms" of agave can be used to infer human occupation and use patterns in areas where the people themselves have disappeared.

Brown et al. use a similar approach in examining the terminology used to describe different forms of squash domesticated in the Americas. They reveal that archaeological evidence is often millennia older than the linguistic terminology, suggesting that names evolve well after use patterns have been established and the people are quite familiar with the species with whom they share their lives.

Also related to issues of how indigenous people see the world is Nabhan's clever and insightful chapter 7, The Wild, the Domesticated, and the Coyote Tainted, which explores differences in perception between hunter-gatherer (Comc'aac) and agrarian (O'odham) Indigenous cultures. Nabhan is significant here as the only person directly mentored by Rea, starting as an undergraduate and continuing to the present. He makes an important distinction between the biological coyote, Canis latrans Say Canidae, and 
two aspects of the Coyote of myth, as both trickster and as the tricked. In some cultural traditions, the last two states might represent opposite sides of the same coin, because even when Coyote functions as trickster, he often ends up the butt of his own tricks. Nabhan discusses how the more agrarian O'odham people are prone to regard wild relatives of domestic flora as inferior variants of domestic forms belonging to coyote, whereas the hunting and gathering Comc'aac regard less useful wild forms as the property or outcome of Coyote's careless or foolish activities. There are quite different interpretations of the role of domesticated forms, with O'odham regarding domesticates as more perfect life forms, whereas the Comc'aac regard domesticated forms as being almost parasitic because they require time and energetic input on the part of humans.

The issue of how different cultures view "wild" versus "domestic" life forms appears in several chapters, including Brown et al.'s discussion of the phylogenetics of domestic squash, Hodgson's examination of the distribution of agaves that were domesticated during pre-Columbian times, and Hunn's examination of how to apply Berlin's folk taxonomic concepts to 'dogs'. The real issue may be "When did the Neolithic begin in the Americas as opposed to other parts of the globe?"

This issue becomes particularly telling in the final essay, by Nancy Turner and her co-authors on the feast tradition in Pacific Northwest First Nations, where almost all foods are taken from nature and there are no domestic forms, because the environment is rich and prolific and the nutritional quality of the gathered foods is high. Feasts consisting almost entirely of non-domestic food types may be a thing of the past because of the social and cultural pressures imposed by US and Canadian production of foodstuffs.

This is a fascinating volume, full of provocative ideas and themes that might be used to develop the future of ethnobiology. I hope that future generations follow up upon traditions established by Amadeo Rea and the authors of this volume. If we succeed, perhaps future generations of O'odham people will see the Gila as once again a river with a functioning riparian zone rejoicing to calls of Ferruginous Pygmy Owls. 